\title{
Gênero nas ciências biomédicas: entrevista com llana Löwy
}

\author{
Caterina Rea \\ Universidade da Integração Internacional da Lusofonia \\ Afro-Brasileira \\ Luzinete Simões Minella \\ Universidade Federal de Santa Catarina
}

Ilana Löwy é bióloga, historiadora das ciências e feminista. É "directrice de recherche" 'senior research fellow' no Institut de la Santé et de la Recherche Médicale (INSERM), em Paris, e autora de vários ensaios sobre as relações entre ciências biomédicas, gênero e feminismo, envolvendo temáticas como a assistência médica à reprodução, história da contracepção e os problemas ligados à utilização dos hormônios como medicamentos. Tivemos a oportunidade de entrevistá-la no dia 6 de dezembro de 2012, em Florianópolis, durante uma das suas missões científicas no Brasil, dando continuidade às suas pesquisas sobre o desenvolvimento das ciências biomédicas no país.' Entre suas obras mais importantes, destacamos:

- GARDEY, Delphine (Org.); LÖWY, llana. L'invention du naturel: les sciences et la fabrication du féminin et du masculin. Paris: Archives Contemporaines, 2000. 227 p. Collection Histoire des sciences, des techniques et de la médecine.

- LÖWY, llana. Cancer des chercheurs, cancer des cliniciens: trajectoire d'une innovation thérapeutique. Paris: Archives contemporaines, 2002. 322 p. Collection Histoire des sciences e techniques et de la médecine.

Copyright $\odot 2015$ by Revista Estudos Feministas

1 A entrevista ocorreu no Hotel Quinta da Bica d'Água. No dia 7 de dezembro de 2012. Ilana proferiu uma palestra intitulada "Saúde reprodutiva das mulheres e questões de gênero na biomedicina", promovida pelo grupo de estudos Gênero, Feminismo e Ciência, formado por integrantes do PPG Interdisciplinar em Ciências Humanas (PPGICH) e do Núcleo de Identidades de Gênero e Subjetividades (NIGS) da Universidade Federal de Santa Catarina (UFSC). 
- LÖWY, llana. Virus, moustiques et modernité: science, politique et fièvre jaune au Brésil. Paris: Archives contemporaines, 2002. 363 p. Collection Histoire des sciences, des techniques et de la médecine.

- LÖWY, llana et ROUCH, Hèlène (Orgs.). La Distinction entre sexe et genre: une histoire entre biologie et culture. Cahiers du Genre, n. 34, L'Harmattan, Paris, 2003. 258 p.

- LÖWY, llana. "Intersexe et transsexualités: les technologies de la médecine et la séparation du sexe biologique du sexe social". Cahiers du genre, L'Harmattan, Paris, n. 34, p. 81104,2003

- LÖWY, llana. L'emprise du genre: masculinité, féminité, inégalité. La Dispute, Paris, 2006. 244 p. Collection Le Genre du monde.

- LÖWY, llana et MARRY, Catherine. Pour en finir avec la domination masculine: de $A$ à Z . Paris: Empêcheurs de Penser en Rond, 2007. 339 p.

- LÖWY, llana. Preventive Strikes: Women, Precancer and Prophylactic Surgery. Baltimore, Maryland: Johns Hopkins University Press, 2009. $344 \mathrm{p}$.

- A Women's Disease: The History of Woman's Disease Cervical Cancer. USA: Oxford University Press, 201 1. 256 p. 
Caterina: Professora llana, agradecemos esta oportunidade de podermos dialogar sobre as suas pesquisas, fundamentais para o campo da história das ciências. Você poderia falar, em linhas gerais, sobre sua trajetória pessoal e intelectual?

llana: Eu sou feminista e meu engajamento está vinculado à minha história pessoal. Nasci na Polônia e logo fui morar em Israel com oito anos. Ao completar 21 anos, mudei para a França, a fim de fazer meu doutorado em biologia no Institut Pasteur de Paris. Me interessei pela história da biologia e sempre fui, ao mesmo tempo, interessada pela políica. Fiz minha tese na área de imunologia clássica e, durante meu pós-doutorado, no Instituto Waizman em Israel, trabalhei sobre a doença de Buerger, ligada à intoxicação por tabagismo. Meu trabalho consistia em tratar de modelizar essa doença a partir de modelos animais. Eu me dei conta de que os modelos assim construídos nem sempre funcionam, como neste caso que estava estudando, pois eles não correspondem à doença humana. Essa pesquisa sobre processos de validação na medicina não me dizia muito, pois ela não falava sobre minha experiência. Comecei, assim, a ler trabalhos teóricos sobre a modelização científica e sobre a epistemologia em geral. Diante dessa dificuldade, foi para mim uma revelação a descoberta da obra de Ludwik Fleck. Para mim, esse autor é alguém que verdadeiramente compreende o funcionamento da ciência, ou seja, como construímos a ciência e o conhecimento científico. Após meu pósdoutorado, voltei para França, onde conheci Bruno Latour. Em 1983, assisti aos seminários de Georges Canguilhem e também encontrei Michel Foucault. Ele estava já muito doente naquele momento, mas ainda recebia seus estudantes e foi muito cordial comigo. Sempre fui bastante eclética, o que me permitiu seguir essas diferentes influências, tratando de encontrar possíveis combinações entre elas. Também comecei a frequentar o seminário de Luce Giard sobre estudos sociais e culturais das ciências. Ela foi uma das primeiras a organizar um seminário sistemático nesse campo na França.

Em 1990, Latour me propôs um segundo pós-doutorado, em São Diego, onde se encontrava o maior departamento de estudos culturais e sociais da ciência. Naquela época, eu já trabalhava no Institut National de la Santé et de la Recherche Médicale (INSERM) e comecei uma pesquisa sobre Fleck e uma outra sobre os transplantes de rins. Latour era professor em San Diego e foi ele quem me recomendou a fazer pesquisa lá, onde encontrei, entre outros, Steven Shapin, historiador e sociólogo das ciências. Naquela época, uma colega norte-americana me propôs trabalhar com o tema mulheres e ciência, mas não quis, pois, nessa época, não tinha ainda interesse em pesquisar sobre a reprodução.

Quando voltei para França, trabalhei com aspectos históricos e sociais do transplante de órgãos, história da 
bacteriologia e da imunologia, história da medicina tropical e com imunoterapia dos cânceres. Minhas reflexões sobre imunologia e medicina devem bastante à obra do Fleck, iniciador da linha de pensamento que compreende a medicina a partir da prática.

Após meus estudos sobre a história da bacteriologia e da imunologia, comecei a pesquisar sobre a febre amarela, depois da minha viagem ao Brasil, onde fui para dar cursos. Comecei um novo trabalho de campo em saúde pública.

Ainda não queria pesquisar sobre as mulheres, não queria saber que existia um problema das mulheres na ciência e que muitas entre elas eram discriminadas. Tive que reconhecer, porém, que a maioria daquelas que eu conhecia e que trabalharam comigo, conseguiram avançar menos na carreira do que os homens. Na França, somente uns 10 a $15 \%$ das mulheres pesquisadoras conseguiam chegar aos graus mais altos da carreira. Existia uma discriminação real. Comecei assim, a me interessar pelas questões ligadas a gênero e mulheres. Nesse interesse entravam também minhas pesquisas sobre câncer, sobre o tratamento diferencial do câncer. Me tornei pesquisadora feminista tarde, mas, desde o fim dos anos 1990, orientei várias pesquisas sobre a intersecção entre gênero e ciência. Comecei a frequentar grupos que trabalham com feminismo e gênero, entrando em contato com Hélène Rouch, Helena Hirata e Eleni Varikas, e tratando, ao mesmo tempo, de criar um diálogo com as ciências biomédicas. Nesta direção, se inscrevem, mais recentemente, na França os trabalhos de Elsa

${ }^{2}$ EIsa DORLIN, 2009 Dorlin sobre medicina colonial e gênero. ${ }^{2}$ Destaco a importância, para mim, hoje, de trabalhar sobre as relações entre gênero e biomedicina na linha dos estudos sociais e culturais sobre as ciências. Entre os autores que considero fundamentais nessa trajetória, menciono aqui os filósofos, sociólogos e historiadores da ciência lan Hacking, Simon Schaffer, Gad Freudenthal, Steven Shapin, Charles Rosenberg, Joseph ben David, Luce Giard e Lorraine Daston, Renée Fox e Evelyn Fox-Keller. Podemos ver que se trata de uma lista eclética de especialistas.

Minha experiência de criança num país como a Polônia, onde vivenciava a discriminação, me marcou profundamente. Eu tinha um aspecto diferente, era uma criança morena de cabelo crespo (bouclé) no meio das outras crianças loiras de cabelo liso. Isso não é por si mesmo um problema, até poderia ser vantajoso, mas naquela ocasião isso não constituía uma vantagem. Pelo menos não para certas pessoas, não para nós. Essa situação me tornou muito sensível para os problemas de discriminação. Ainda hoje penso dessa forma, não posso aceitar facilmente as discriminações. Não consigo aceitar as discriminações de classe e as injustiças sociais, por exemplo, no que tange ao acesso à saúde, que, em muitos contextos e países, não é o mesmo para os ricos e para os pobres. Na França, se as 
pessoas pobres vão para o hospital, podem ter comida não muito boa ou podem ter quartos barulhentos, mas, em regra geral, elas têm acesso aos mesmos serviços que no setor privado e às vezes, até mesmo melhores -, o que não é o caso em outros países. Talvez, no setor particular, a França tenha problemas de supermedicalização, uma medicalização inútil, mas aqui, no Brasil, por exemplo, no caso da gravidez, as mulheres devem enfrentar várias dificuldades por conta da não legislação do aborto.

Luzinete: A discriminação na assistência médica é muito forte aqui, sobretudo no caso de mulheres pobres, mulheres não brancas.

Ilana: Eu, que tenho uma perspectiva mais politizada, acho difícil de entender como os médicos progressistas não se revoltam contra a penalização do aborto.

Luzinete: Parece que o grande desafio para os feminismos é pensar não tanto por que as pessoas religiosas, sejam médicos/ as ou leigos/as (que têm um vínculo religioso forte) são contra o aborto, mas por que pessoas que não têm vínculos religiosos são também contra. Não no discurso necessariamente, mas nas atitudes...

llana: De fato, não é verdade que seja assim apenas por causa do vínculo religioso. Eu fui dar uma vez uma palestra num congresso na Polônia, no congresso europeu de bioética; como eu falo polonês, me deram a presidência de uma mesa sobre aborto ou sobre o caráter sagrado da vida. Eu entrei em discussão, pois muitos eram religiosos e contra o aborto. Muitos eram padres. Coloquei o tema em discussão, mas fui defendida por um professor de Louvain que era jesuíta e médico. A única pessoa que, naquela ocasião, defendeu abertamente minha posição no meio de outros religiosos foi esse jesuíta de Louvain, dizendo: "pessoalmente, eu sou contra o aborto..., mas se uma mulher quer abortar num contexto no qual isso é ilegal, ela vai abortar de toda maneira, mas ela vai fazê-lo em condições mais perigosas para ela. Isso vai ser um pecado duplo: um relativo ao aborto e outro relativo ao perigo para sua vida. Então, é melhor um só pecado". Por isso que não acredito que seja necessariamente determinante 0 vínculo religioso.

Uma outra colega francesa, que trabalhou comigo, aceitou a interdição do aborto no Brasil. Para ela, o diagnóstico de malformação fetal representa uma situação muito difícil para as mulheres que o recebem, e os médicos brasileiros do SUS fazem tudo o que podem para as mulheres grávidas que receberam

${ }^{3}$ Véronique MIRLESSE et Isabelle VILLE, 2013. tal diagnóstico. Segundo essa colega francesa, ${ }^{3}$ o fato de ser explicado para as mulheres brasileiras (e pobres) qual é o problema do feto pode constituir, pelo menos aos olhos dos médicos brasileiros, uma forma de empoderamento, de ajudar essas 
mulheres a viverem uma situação impossível. Porém, para mim, isso não é empoderamento, é desempoderamento, visto que há outras soluções. Se a mulher não estava em condições de escolher, de ter acesso livre a outras soluções, isso não é empoderamento para mim.

Assim, minha biografia ajudou-me a dizer um não a situações de discriminação. São inaceitáveis...

Caterina: Sim, ainda mais num setor fundamental como o da saúde, que deveria ser um direito básico...

llana: Não consigo entender por que muitos médicos, mesmo os mais dedicados e completamente progressistas, aceitam, em muitos contextos, essa situação e não fazem uma rebelião organizada. Não digo para a liberação do aborto de uma forma geral, que constitui um problema político, no Brasil, que não é da competência dos médicos, mas para casos de malformações fetais graves. Não é um número muito alto... Isso pode ser feito para evitar alguns milhares de tragédias horríveis.

Luzinete: Parece-me que você pensa sobre diferentes planos simultaneamente: gênero, ciência, práticas científicas, formas de discriminação...

Ilana: Quando se fala em interseccionalidade, nós entendemos a articulação de classe, raça, gênero/orientação sexual. Aqui, eu falo de multidimensionalidade do problema. Trata-se de um problema com múltiplas dimensões. Por exemplo, essas malformações fetais podem ser identificadas porque as técnicas de ecografia melhoraram incrivelmente, e nós percebemos cada vez mais coisas, mas não sabemos sempre os significados daquilo que vemos. Isso se torna um problema nos países onde o aborto por malformação fetal é permitido. Fala-se para a mulher que há um problema com o feto, mas às vezes não se pode dizer para ela se será grave ou não. Esta situação produz muita angústia. Aqui no Brasil, estas técnicas estão chegando, na Fiocruz há máquinas bastante boas para ver as malformações fetais, ainda que as melhores estejam no setor privado. Mas não se pode fazer nada... Legalmente, mesmo se a malformação é grave, a mulher é obrigada a continuar a gravidez. Agora, pode-se intervir no caso da anencefalia, o que é um progresso, mas isso representa um percentual muito baixo. E também há problemas de doenças infecciosas ligadas à pobreza que engendram malformações. Na França, isso é muito raro, mas, em geral, nesses casos, o médico propõe a interrupção da gravidez. Aqui no Brasil há malformações congênitas para se pesquisar que, há trinta ou quarenta anos, vemos só muito raramente na Europa.

Caterina: Você pode falar sobre seu interesse pela América Latina e particularmente pelo Brasil? 
Ilana: Gosto da América Latina e sou apaixonada pelo Brasil... não somente por Copacabana. Mas, falando seriamente, me interessa muito a realidade do Brasil por razões políticas, pois é um lugar politicamente muito interessante. Um lugar também complexo, mas muito interessante, onde muitas coisas acontecem. Passa a impressão de ser um lugar aberto, onde coisas interessantes ainda podem se desenvolver. Mas também porque acredito fortemente na importância de fazer trabalhos comparativos. Ajuda muito comparar os diferentes contextos. Há poucos estudos comparativos ainda. No Brasil há duas linhas de pesquisa na minha área: há muitos estudos gerais ou abstratos, muito bons no campo da epistemologia geral e da filosofia da ciência, e há trabalhos específicos consagrados ao Brasil, mas ainda tem-se poucos estudos comparativos. A abordagem comparativa é muito importante, porque, para estudar o presente, é importante termos distanciamento. Como criar essa distância? De duas maneiras: viajando e mudando de lugar, por exemplo, analisando a medicina francesa do ponto de vista da medicina norte-americana ou estudando o Brasil - como eu gostaria de fazer - do ponto de vista da Polônia. Na Polônia também, o problema da saúde das mulheres está influenciado pela presença da Igreja católica. Claro, existem tradições muito diferentes, pois ambos têm um passado político muito diferente, inclusive a experiência do comunismo na Europa do Leste. Gostaria de estudar problemas como contracepção, aborto, diagnóstico pré-natal, comparando a Polônia com o Brasil. Adriana Petryna já fez isso comparando esses dois países do ponto de vista de testes clínicos de substâncias e medicamentos. Esse tipo de estratégia é bem importante para entender o que acontece ao se ter distanciamento do ponto de vista histórico e comparativo. Essa posição permite um olhar diferente, uma maneira diferente de ver.

Caterina: Quais são suas referências maiores, os autores que mais tiveram importância para você no campo dos estudos biomédicos e dos estudos de gênero? Ou seja, quais as referências que você ressaltaria na articulação entre medicina, biologia e gênero?

llana: Antes de todos, Ludwik Fleck. Foi ele que me dirigiu para o estudo da história da ciência. E também todos os clássicos de história e filosofia da ciência e Science Studies, como Steven Shapin e Simon Schaffer, lan Hacking. Com certeza também Foucault e Canguilhem foram fundamentais, e mesmo Latour, que me introduziu nessa disciplina, sem esquecer de Callon. Fui aos seminários deles no começo. Todos os fundadores dessa escola que se chama dos estudos sociais e culturais da ciência. Conheci Hacking quando ele esteve na França. Mas esses autores são para mim referências fundamentais. 
Luzinete: Aqui no Brasil creio que os mais conhecidos são Foucault, Canguilhem e Latour...

llana: lan Hacking não é conhecido? É filosofo da ciência e trabalhou sobre experimentos, história da saúde mental e epistemologia. Ele ocupa a cátedra de Foucault no Collège de France na história e na filosofia dos conceitos científicos. Também é para mim uma referência Hans Joerg Rheinberger e Loraine Daston do Max-Planck-Institut für Wissenschaftsgeschichte. E para os estudos sociais da ciência, com certeza, foi fundamental Evelyn Fox-Keller. Conheço ela muito bem, embora a tenha conhecido tarde. A leitura de seu trabalho foi muito importante para mim.

Luzinete: E Margaret Rossiter?

Ilana: Autoras como Margaret Rossiter, Londa Schiebinger, Angela Creager são muito boas, mas não foram referências intelectuais centrais para mim. E para meu desenvolvimento como historiadora, ressalto Charles Rosenberg, que é professor de História da Medicina de Harvard - seu pensamento me ajudou muito -, e também Gad Freudenthal, que é especialista da ciência árabe-judia da ldade Média. Nesse período ele trabalhou com Joseph Ben David, pioneiro da sociologia das ciências, e foi aluno dele. Encontrei Ben David só uma vez, (não tinha com ele um contato direto, como o tinha com Gad Freudenthal) com quem aprendi muito. Outras referências para mim, no contexto francês, foram Luce Giard e Michel de Certeau; mas, no caso desse último, apenas através dos seus escritos.

Luzinete: Quando você esteve em San Diego, teve oportunidade de conhecer as pesquisas sobre cientistas negras norteamericanas? Lembro, por exemplo, do livro de Winifred Warren sobre 100 mulheres negras cientistas que se destacaram nas suas respetivas áreas científicas, como biologia, medicina, química, física etc. O que me chamou a atenção nesse livro é que há indicações sobre a importância delas para mudanças nos enfoques desses campos científicos.

llana: Não, sobre este aspecto não conheço nada. Na verdade, eu não trabalho com a área "Women in Science". Trata-se de áreas separadas: "Women in Science" e "Gender and Science", que são áreas bem diferentes. Minha especialização é mais na intersecção entre gênero e ciência, em particular, as ciências biomédicas, com seus conteúdos e sua história. Para mim, a questão é a conjuntura e a coconstrução social entre o conhecimento das ciências biomédicas e conhecimento sobre gênero. Uma referência que posso citar e que conheço pessoalmente é Evelynn Hammonds, que trabalha em Harvard sobre intersecção entre raça e campos acadêmicos das ciências e, particularmente, da medicina. Eu a conheci na época do meu quarto pós-doutorado, que foi justamente em Harvard.

484 Estudos Feministas, Florianópolis, 23(2): 477-496, maio-agosto/2015 
${ }^{4}$ Sandra HARDING, 2001.

${ }^{5}$ Charles ROSENBERG and Janet Lynne GOLDEN, 1977.
Caterina: O ponto de encontro destas duas perspectivas, "Women in Science" e "Gender and Science", poderia ser talvez a questão de saber se as mulheres na ciência produzem algumas formas de conhecimento diferentes, a partir da experiência da discriminação e da reflexão sobre sua própria condição de mulheres num âmbito muito androcêntrico e masculino...

llana: Sim, essa é a reflexão de Sandra Harding. Tenho um artigo bastante pedagógico que escrevi em francês no livro que editei com Delphine Gardey sobre a invenção do natural. Nesse artigo, trato de explicar isso. Esse artigo foi traduzido para o português nos Cadernos Pagu.

Luzinete: Da Sandra Harding, lê-se muito aqui uma tradução em espanhol, uma versão que foi publicada em Buenos Aires. ${ }^{4}$ Ilana: É um texto muito epistemológico, no qual Sandra Harding retoma as teses de Donna Haraway, mas essa é a questão que Londa Schiebinger discute, assim como Angela Creager. A questão é o impacto do feminismo e da entrada das mulheres nas ciências. Aprecio muito o trabalho de Londa Schiebinger e seu questionamento sobre se o feminismo mudou a ciência, mas não posso dizer que ela seja uma referência para mim, nem que ela tenha mudado minha reflexão, minha maneira de ver as coisas. Charles Rosenberg teve mais influência para mim por conta de seu conceito de framing desease ${ }^{5}$ (quadro da doença), ou seja, de cada doença é uma criação sociobiológica e cultural, e como articular essas dimensões. Também Hans Joerg Rheinberger trabalhou sobre observações científicas e lan Hacking sobre a prática científica.

Luzinete: Tudo isso é muito apaixonante...

llana: A impressão que às vezes tenho, trabalhando neste campo de estudos sociais da ciência, é de estar sentada no ombro dos gigantes.

Caterina: Muitos de seus textos evocam a ideia de uma invenção do natural. O que você entende com esta noção? Seria a ideia de desconstruir a crença em uma natureza prédada, anterior às produções culturais e humanas? Você pode falar um pouco sobre isso? Quando falo de desnaturalização, quero dizer que não existe uma dimensão supostamente primeira e natural, como uma origem que seria anterior ao que os seres humanos constituem sócio-historicamente.

llana: Sim, mas este é um problema que me preocupa pouco. Mas não acho que a questão seja a desnaturalização, acho que os seres humanos sempre artificializaram de formas diferentes. A divisão entre natureza e cultura existe desde sempre. Tem um texto de Loraine Daston sobre este tema da invenção do natural. A noção de natural mudou nas diferentes épocas, esta posição é bem feminista. Fala-se que a mulher é mais 
${ }^{6}$ Marcela IACUB, 2002

${ }^{7}$ Marilyn STRATHERN, 1992. próxima da natureza, mas a natureza do século XVIII não é mais a natureza do século XIX. O que era entendido por natureza era muito diferente. A natureza do século XVIII era uma natureza flexível, e o projeto era de melhorar a natureza. A natureza do século XIX é a das leis naturais. E isso é outra coisa.

Caterina: Então a natureza é uma construção humana. É bem isso que queria dizer usando o termo desnaturalização.

llana: Sim, mas não acho que haja mais natureza na aplicação de determinadas técnicas do que na aplicação de outras. Nós sempre desnaturalizamos e sempre fizemos a diferença entre natural e cultural, mesmo que de formas diferentes. As reconstruções são diferentes.

Caterina: Mas a mesma diferença e dicotomia entre natural e cultural é, ela mesma, cultural e social.

Ilana: Com certeza. Isso foi o que aprendi com Canguilhem quando frequentei seu seminário. Foi uma das primeiras coisas que nos ensinou, que a ciência não se encontra na natureza, que a ciência é um discurso sobre o discurso. Ele dizia que a ciência é um discurso sobre a natureza, então não é natural, pois implica o discurso, algo que os seres humanos constroem. O que queria acrescentar é que isso não implica a desnaturalização no sentido de Marcela lacub. ${ }^{6}$ Não concordo com ela. Não acho que há um grau mais elevado de artificialidade, mas sim a criação de coisas novas pela técnica. Se as técnicas mudam, as maneiras de construir as coisas mudam também. Nesse caso, a boa referência é Marylin Strathern. Ela escreveu After Nature, que é um livro muito bom. ${ }^{7}$ Ela afirmou coisas fundamentais sobre esse assunto do ponto de vista antropológico. Além de Strathern menciono Sarah Franklin, uma estudante de Strathern, hoje professora na Universidade de Cambridge. Ela é uma feminista.

Luzinete: Mas, ao pensar sobre a técnica, você acha que Walter Benjamin constitui uma referência nos Estados Unidos? llana: Claro, Walter Benjamin é muito conhecido, mas não nesse contexto. Mas eu adoro Walter Benjamin. Ele é mais usado para refletir sobre arte, literatura. Em relação às novas tecnologias de reprodução, concordo com as posições de Daniel Borrillo, mas discordo de Marcela lacub. Essas posições são bem diferentes. Tenho um artigo sobre como construímos a noção de idade da maternidade e de mães velhas. Trabalho com Nathalie Bajos a propósito da contracepção e com uma professora brasileira da Fiocruz, Claudia Bonan. Vamos fazer uma pesquisa juntas.

Caterina: Você poderia falar sobre outras influências centrais no desenvolvimento das suas pesquisas?

llana: Acho que Donna Haraway é muito importante. Conheço a obra de Sandra Harding, mas não segui muito, eu fui muito 
${ }^{8}$ Donna HARAWAY, 1989.

${ }^{9}$ Donna HARAWAY, 1991.

${ }^{10}$ Nelly OUDSHOORN, 1994

1 Entrevista realizada por llana Löwy, "La science ne doit plus se décliner au masculin. Entretien avec Evelyn Fox Keller", publicada em Mouvements des Idées et des Luttes, v. 4, n. 17, 2001, p. 117 124 mais influenciada por Donna Haraway. O pensamento dela me interessou muito, embora eu ache que as últimas coisas que ela produziu sejam menos interessantes, mas seu livro Primate $V_{\text {Visions }}{ }^{8}$ me marcou muito. Não conheço pessoalmente Donna Haraway, eu a vi uma vez, mas seu livro Primate foi uma revelação para mim. Os outros livros menos, como Manifesto Cyborg, ${ }^{9}$ que considero interessante, mas me marcou menos. Mas o livro sobre primatologia é extraordinário. Escrevi meu primeiro livro no momento em que estava lendo esse texto.

Outras referências para mim são Nelly Oudshoorn e Adele Clark. Nelly Oudshoorn é holandesa, de Amsterdã, e seu trabalho mais conhecido é Beyond Natural Body, sobre hormônios. ${ }^{10}$ Tratase de um livro muito importante. Adele Clark é biomédica e trabalha sobre questões de biomedicalização. Ela é feminista...as duas são, na verdade; mas Adele Clarke é muito importante, ela é também socióloga e estudou com Anselm Strauss. É feminista na sua análise da noção de biomedicalização. Nesse artigo que publiquei nos Cadernos Pagu cito todas essas referências. Nelly participou desse livro em francês que mencionei: L'invention du naturel. Fiz uma entrevista com Evelyne Fox-Keller ${ }^{11}$ na revista Mouvements. Evelyn Fox Keller é muito interessante. Hoje ela se interessa mais pela teoria, escreveu um livro sobre modelização biológica e sobre o conceito de genes.

Caterina: Qual é a influência do feminismo e de outros movimentos sociais sobre o desenvolvimento das ciências biomédicas?

llana: Isso é interessante, embora não trabalhe diretamente com esse tema. Mas posso dizer uma coisa que acho que é importante, me baseando no trabalho de colegas, como Janine Pierret, Geneviève Paicheler, colegas de meu departamento. Elas descobriram que o movimento ligado à AIDS cobre uma pequena parte das doenças. Temos um problema geral de representatividade com os movimentos sociais. Minha colega Diane Paul, que é historiadora de eugenia, investiga os movimentos de enfermos de doenças raras. A militância dessas pessoas nem sempre possui representatividade (ou é suficientemente representativa). Ela mostra que muitas vezes as pessoas com doenças, particularmente as mulheres, não têm voz nem visibilidade. Na França, acontece muito, pois a maioria das mulheres com AIDS são africanas, pobres e não falam francês. São invisíveis porque não há mulheres negras que pesquisem sobre o tema. Não conheço nenhuma socióloga negra, conheço algumas que são de origem magrebina, mas não conheço pessoalmente nenhuma mulher pobre e negra que trabalhe sobre essas questões.

Luzinete: Mas aqui também, llana, nós temos poucas exceções como Jurema Werneck, que reflete sobre a saúde da 
${ }^{12}$ Ian HACKING, 2006.

\footnotetext{
${ }^{13}$ Margareth LOCK, 1993.
}

população negra. Quem pesquisa sobre anemia falciforme é uma aluna de Marcos Maio Schor, Fátima de Oliveira, mas isso é muito raro. Em geral, a maioria dos trabalhos abordam as questões de gênero e classe nas intersecções, mas dificilmente incluem a questão da saúde de uma forma mais sistemática. llana: Tem também Ricardo dos Santos, além de Fátima de Oliveira. Gosto muito do trabalho de ambos, mas enfatizam a questão da identidade e da saúde pública. Tem muito pouco de técnica... Tenho uma ex-doutoranda, Ana Carolina Vimeiro, que está começando uma pesquisa nessa direção. Ela é professora em Minas Gerais e trabalha sobre problemas de biotipologia e formação racial. Ela dá atenção à técnica e ao desenvolvimento de métodos de classificação. Um aspecto muito importante nos estudos sociais da medicina é a classificação, ou seja, como se constrói uma classe de pessoas. Por isso Hacking é tão importante: ele fala de making up people ou seja, a fabricação de pessoas. ${ }^{12}$ Hacking é historiador da estatística entendida como maneira de fabricar pessoas, making up people. Estou muito interessada nas classificações, ou seja, no método para classificar objetos, como se criam classes. Uma coisa que é muito importante, para mim, nos estudos culturais e sociais da ciência, é como métodos e técnicas produzem classes de pessoas.

Caterina: Quais são os principais efeitos, mesmo paradoxais, dos movimentos ligados à saúde, em particular à saúde das mulheres? Existe hoje um risco de medicalização excessiva ligada à medicina preventiva?

Ilana: Adele Clark é, provavelmente, a melhor referência para responder a essa questão. Organizei com uma colega, Nancy Krieger, professora de epidemiologia em Harvard, um workshop sobre o tratamento hormonal da menopausa. Ruth Hubbard é uma das pioneiras deste campo de biologia e ciência, tem um discurso emocional sobre isso, ou seja, quando nós fundamos "our body, our self" em Boston, no final dos anos 1960, para nós essa expressão significava "nosso corpo somos nós mesmas". Tentávamos nos libertar do poder dos médicos, conquistar formas de empoderamento. Hoje, esse mesmo movimento é para sermos consumidoras conscientes de saúde. Transformou nosso corpo em nosso inimigo. As mulheres devem fazer tudo para ter precaução. A hipermedicalização é apresentada como uma forma para as mulheres conservarem seu corpo no melhor estado possível. Essa é uma reivindicação que hoje está associada com o feminismo e que afirma uma ideia de que a medicina tem boas razões, é amiga das mulheres, pois as ajuda a consumir muito. Uma outra referência sobre esse aspecto é Margaret Lock, antropóloga canadense que afirmou isso com muita clareza no seu livro Encounters with Aging. ${ }^{13}$ Trata-se de um livro, muito conhecido nos Estados Unidos, sobre o tratamento 
14 Michel CALLON; Pierre LASCOUMES; Yannick BARTHE, 2001. hormonal da menopausa no Japão e nos Estados Unidos. Lock introduziu uma noção muito interessante, a de local biologies: a biologia não é universal, mas local. Isso quer dizer que a cultura produz e forma os corpos, não só como nós os entendemos na dimensão simbólica, mas literalmente produz corpos. Por isso, temos que falar de biologias locais.

Luzinete: Esse discurso médico sobre menopausa é criticado, por exemplo, pelas mulheres indígenas, que não se reconhecem nele.

llana: É exatamente esse o ponto do livro da Margaret Lock. Um historiador da ciência alemão, Michael Stoller, fez um trabalho muito bom sobre a percepção negativa da menopausa no Renascimento. Ele não concorda com Londa Schiebinger em alguns aspectos. Gosto muito de Michael Stoller, que é um historiador muito sério.

Caterina: Qual a relação entre expertise científica e democracia? Como isso influencia os processos de medicalização e medicalização excessiva de muitos aspectos da nossa vida? llana: O problema é que hoje a medicina é muito forte, a ideologia médica é muito presente, especialmente aqui no Brasil. Tenho dois alunos que pesquisam sobre cesariana: é inacreditável observar como aqui o parto foi medicalizado sem nenhuma resistência, principalmente nas classes médias.

Caterina: Muitas vezes, nos seus trabalhos, você fala da importância do princípio da "contra-expertise" mesmo em relação a questões de saúde. Como se constitui hoje a oposição entre "expertise" e "contra-expertise"? Como essa oposição aparece nos diferentes contextos sociais, históricos e políticos, nos quais você tem trabalhado?

llana: Não sou especialista nesse assunto. Posso citar a referência de Michel Callon e Pierre Lascoumes. O livro deles é muito bom. ${ }^{14}$ Conheço bem Michel Callon, pois o encontrei quando ele começou com Bruno Latour, esse pequeno grupo, na metade dos anos 1980, que se chama Pandore e que iniciou na França os estudos sociais da ciência. Gosto muito da obra de Michel Callon. Quanto ao Latour, ele produz hoje na área de filosofia geral e filosofia da modernidade. E a produção de Latour não é muito politizada, acho que a de Callon é muito mais.

Caterina: Você trabalha no campo da epidemiologia e particularmente sobre questões relativas à prevenção de enfermidades que atingem as mulheres, como o câncer de mama. O que é entendido por prevenção nos diferentes contextos sociais e históricos? Qual é o impacto das indústrias farmacêuticas na definição desse termo e suas estratégias de atuação? 
llana: Não sou epidemiologista, trabalho com epidemiologistas, o que é outra coisa. O que posso dizer, a partir de Charles Rosenberg e outros historiadores da medicina, é que agora as técnicas novas da medicina eliminam as fronteiras entre doença e riscos. Este é o tema de um dos últimos livros que escrevi, ou seja, como a fronteira entre doença e risco desaparece. Como se trata de mais e mais riscos de doenças, isso afeta também o diagnóstico pré-natal. No diagnóstico pré-natal, há casos de acefalia, ausência de rins, que se veem na ecografia, tem-se a certeza da presença dessas malformações. No caso de doenças como a de Down, o diagnóstico é quase seguro, mas há muitas (e haverá outras mais) para as quais não há diagnóstico, mas há, contudo, diagnóstico de riscos. O médico diz que tem tal problema genético - não gosto do termo genética, pois não tem a ver com famílias - mas podemos falar que há tal mutação e que a metade das crianças não exprime essa mutação, pois o gene não é ativo. Assim é na biologia: $50 \%$ não têm problema e os outros $50 \%$ têm problema. Agora, desses $50 \%$ que têm algum problema, $10 \%$ estão com uma doença muito grave, $40 \%$ com uma menos grave e o $50 \%$ restante não têm praticamente nada ou apenas um problema bem leve que pode ser curado.

Então, o que se pode fazer num país onde o aborto é legal? Tem-se um risco de $10 \%$ de crianças com doenças gravíssimas. Não no sentido de que essas crianças vão morrer, esse não é o problema. Possuem doenças como a hérnia diafragmática, devido à qual, na França, a metade das crianças portadoras morre no momento do nascimento, porque a operação para corrigir esse problema falha; mas aqueles que sobrevivem não têm sequelas. A grande maioria dos pais escolhe esperar o nascimento, mesmo sabendo que vai ter um grande risco de a criança não sobreviver. É difícil para os pais, mas não é um problema ético grave, embora muitos pais possam ter depressão e angústias. O problema é o quanto a pessoa vai ser enferma, e não sabemos o seu nível de gravidade. Esse é o caso da deficiência. Muitos acham que esse problema é fácil e que só precisaria mudar a sociedade para integrar as pessoas com deficiências. Essa é a teoria: como lidar com crianças com deficiências graves? A sociedade deve acolhê-las, sim, mas com frequência, na prática, a mãe deve parar tudo para se ocupar da criança e, mesmo que seja de nível econômico bastante alto, deve lutar para garantir os custos. E tem o problema das deficiências intelectuais: algumas crianças até conseguem ser felizes, outras menos; algumas delas podem ter angústias ou depressão, mas o problema maior é para a mãe, pois não se tem reciprocidade de care (cuidados), a relação nesse caso vai só numa direção. Normalmente, quando nós temos crianças, chega um momento em que não há mais dependência de outras pessoas para viver. No caso das deficiências graves porém, há 
${ }^{15}$ Gilbert WELSH; Liza SHWARTZ and Steven WOLOSHIN, 2011.

${ }^{16}$ Alexander EDMONDS, 2010. dependência de vida sem reciprocidade de care. Pode haver reciprocidade afetiva, mas não de care. Durante toda a vida é a mãe, em geral, a que tem que cuidar. Vejam como o problema do risco é central para o diagnóstico pré-natal e também para outras doenças como o câncer.

Luzinete: Sim essa ideia do risco é fundamental, o medo, o temor do risco ambiental ou da catástrofe e mesmo da doença. Esse temor envolve uma concepção do mundo.

llana: Isso é mais complexo, pois hoje a maior parte da medicina é preventiva, e muito da medicina preventiva é excelente. O problema não está aqui. A questão é do overtreatement, o ultratratamento dos riscos porque existe o medo. Nos Estados Unidos, por exemplo, os médicos têm medo de processos penais, o que se chama medicina defensiva. Tem um grupo de colegas epidemiologistas que fizeram um trabalho muito bom. Menciono aqui Gilbert Welch, que discute a questão do overtreatement. O livro que ele publicou com Lisa Schwartz e Steven Woloshin se chama Overdiagnosed. ${ }^{15}$ Eles explicam que a indústria farmacêutica está claramente muito interessada nessas dinâmicas, mas não é só para obter lucro, isso seria uma simplificação. O processo é bem mais complicado do que a dimensão do lucro. Por exemplo, há a ideia de que a cesariana envolve menos riscos do que o parto natural. A explicação mais fácil dessa crença seria dizer que os médicos priorizam a cesariana porque é mais fácil, controlada e mais lucrativa: não precisam trabalhar à noite, não há mais emergências. Também existe verdadeiramente uma demanda por parte das mulheres que querem evitar efeitos imprevistos. Minha hipótese é que, aqui no Brasil, em particular, há uma ideologia científica, uma cultura cirúrgica, como no caso de cirurgias plásticas. Como mostrou o antropólogo Alexander Edmonds, aluno de João Biehl, no seu livro Pretty Modern, ${ }^{16}$ no Brasil, inclusive para pessoas que não são muito ricas nem de classe alta, fazer cirurgia plástica é uma maneira de tomar cuidado de si (podemos usar o termo foucaultiano soin de soi). A partir dessa cultura de cirurgia, é mais fácil introduzir o parto cirúrgico, como no caso da cesariana, em que tudo é planejado para a hora marcada, higienizado, sem contato com o sangue. E logo a mulher faz uma cirurgia plástica para reparar as consequências da gravidez e da amamentação. E tudo isso seria uma forma de soin de soi (cuidado de si). No Brasil, particularmente no Rio, percebi como isso está ligado a uma cultura da maternidade. Existe a expressão "nenê de colo"; se a mãe tem sempre a criança de colo, não pode fazer nada, não pode trabalhar.

Como escrevi com Hélène Rouch, na introdução de nosso livro, ${ }^{17}$ a noção de gênero é um sistema de símbolos que denotam diferentes relações de opressão. Gênero pode ser interpretado como sistema de opressões, estou de acordo com Christine Delphy, e com o feminismo materialista. 
${ }^{18}$ Raymond WILLIAMS, 1985.

19 Steven SHAPIN and Simon SCHAFFER, 1985.
Minha compreensão de gênero inspira-se na definição de classe social de Raymond Williams. Ele é um historiador cultural inglês e explica, no seu livro Keywords, ${ }^{18}$ que a expressão classe social iniciou-se como um termo descritivo para falar da classe de artesãos, da classe de camponeses, da classe dos guerreiros, ou seja para dar uma descrição de diferentes ocupações. O termo classe implica também a descrição de formas de hierarquia como classe superior, média e inferior. Então, a partir de Marx, esse autor explica que não se trata apenas de hierarquia, mas também de uma coconstrução de hierarquias de opressão; ou seja, a classe de camponeses e a classe de proprietários agrários são construídas conjuntamente numa relação de opressão. A classe capitalista e a dos trabalhadores são construídas conjuntamente numa relação de opressão e de exploração. O mesmo vale para o gênero, que se construiu como diferenças escolhidas para construir uma dominação. Diferenças existem, mas a dominação é construída. É uma coconstrução: o feminino é construído contra o masculino numa relação de dependência e de dominação, segundo destacam também Evelyn Fox-Keller e Christine Delphy.

Luzinete: Joan Scott também fala de gênero como atribuição de significados ligados à dominação.

llana: Sim, várias teóricas começaram a escrever isso ao mesmo tempo na década de 1970. Falava-se de langage genré. Evelyn Fox Keller escreveu bastante sobre as construções da linguagem. Eu trabalho menos com a categoria de linguagem, pois não sou filósofa, nem psicóloga ou psicanalista. Sou cientista de bancada, mas estou completamente de acordo com essas análises. Como afirmam Shapin e Scheffer, no livro que eles publicaram, as práticas materiais, sociais, literárias e das ciências são construídas conjuntamente. ${ }^{19}$ As práticas literárias são a linguagem. Fleck escreveu sobre isso. Vale a pena ler Fleck.

Caterina: Em que medida o novo interesse das ciências biomédicas pelo tratamento de pessoas intersex ou trans conduziria a desestabilizar as categorias e representações dicotômicas da biologia?

llana: Essa é uma questão interessante, mas a dominação masculina é um pouco como as cabeças de hidra. As questões trans ajudam a cortar mais uma cabeça, mas não estou segura de que não crescerá uma outra, pois a dominação masculina é muito resistente. Essa ambiguidade é bem visível no Brasil. Por um lado, tem-se uma aceitação maior da homossexualidade, de pessoas trans e bi, de todas as cores do arco-íris; por outro lado, vejo uma ideologia materna muito forte como essas mulheres que fazem diagnóstico pré-natal, pagando muito caro, só para descobrir o sexo do bebê, saber se deve comprar a roupinha azul ou rosa. Tem uma contradição importante aí. 
Estou impressionada pelo fato desta dupla direção: maior tolerância e conservadorismo.

Caterina: Na verdade, minha questão era mais voltada a perguntar se essa parte da medicina que lida com intersexualidade ou transsexualidade pode abrir uma nova visão do campo biológico, que não seja a diferencialista.

llana: Pode sim, claro que pode.

Caterina: Penso em autoras como Anne Fausto-Sterling, por exemplo.

llana: Pode, mas acho que a questão é mais complexa. Antes de tudo, intersex não é trans: são duas condições bem diferentes. Concordo com Elen Feder, que é uma teórica das questões trans e intersex, que explica que o problema dos/das intersex foi igualizado com a homossexualidade. Mas tem diferenças. A maioria das pessoas intersex e das crianças tem doenças, e até mesmo doenças bastante sérias. O problema é que a militância intersex focalizou os órgãos genitais, mas os verdadeiros problemas para essas pessoas não são somente os órgãos genitais. O problema não é a diversidade da sexualidade, o problema é ter um corpo diferente, talvez ter doenças crônicas muito mais frequentes. Não é a sexualidade, o problema... O movimento intersex paradoxalmente pode tornar as coisas mais difíceis para algumas dessas pessoas. Militantes formam só uma parte e não são sempre representativas/os de todas/os no grupo de intersex. Militantes intersex são pessoas que simplesmente têm órgãos sexuais atípicos, mas as outras pessoas intersex, que estão mais doentes, não militam tanto.

Luzinete: Parece-me algo conservador tentar combinar identidade de gênero com orientação sexual..

Ilana: Esse ponto é interessante, porque essas duas ideias foram dissociadas. Agora, a identidade de gênero não é alinhada mais com a orientação sexual. Esse ponto mudou, e o movimento homossexual contribuiu para essa mudança.

Luzinete: Sim, mas acho que devemos tentar problematizar uma lógica que me parece quase combinatória. Esse corpo agora tem que combinar com aquela identidade; ou seja, de alguma forma, tem que entrar na norma.

llana: Mas essa é mais uma questão para a transsexualidade...

Caterina: O que estamos falando aqui é outra coisa, é a imposição de uma operação de reatribuição de sexo para intersex, que, segundo falam as/os militantes, nem sempre escolheram serem operadas/os...

llana: Para a normalização dos órgãos sexuais, estou bastante de acordo na necessidade de operar, por uma razão prática, 
${ }^{20}$ llana LÖWY, 2013. pois esses órgãos não funcionam bem... Quanto à pergunta da Luzinete, concordo que algumas transexuais acabam reforçando a visão estereotipada do gênero, mas não todas, pois há várias transexuais que são também transgender.

Por outro lado, eu fiz um trabalho histórico sobre um caso de intersex - que chamavam de hermafroditas, no começo do século XX, na França. ${ }^{20}$ Trata-se de um caso muito interessante de um jovem que foi verdadeiramente hermafrodita. Ele foi criado como homem, se considerava homem e tinha órgãos sexuais atípicos. Podia se masturbar, mas não teve relações sexuais. Não se casou, mas teve uma vida social normal. Ele tinha amigos homens, ia a restaurantes com eles e praticava esportes masculinos. No começo de século XX, foi possível não ter relações sexuais, havia muito mais pessoas solteiras naquela época do que hoje, ou que não tinham relações sexuais ou muito poucas. E isso era socialmente aceitável. Essa condição era mesmo considerada, por alguns, como uma coisa boa, como expressão de uma pessoa virtuosa, controlada, com temperamento moderado. Nesse período, o corpo não era muito visível. Temos casos descritos de pessoas intersex que não sabiam que seus órgãos genitais eram anormais, pois não tinham uma outra pessoa para comparar. As pessoas iam pouco à praia, usavam vestimentas que cobriam o corpo inteiro, em particular no interior, tomavam banhos raramente e com camisa - tinha-se o costume de tomar banho com a camisa por modéstia. Ninguém podia saber se eles tinham órgãos genitais atípicos.

Agora, as coisas mudaram porque vivemos numa sociedade hipersexualizada, e não ter relações sexuais é percebido como algo patológico. Essa situação faz com que as pessoas se focalizem nos órgãos genitais. Essa focalização, porém, pode ser algo não positivo para elas. Quem tem hiperplasia adrenal, que é a condição mais frequente nas pessoas intersex (Congential adrenal hyperplasia-CAH), deve fazer tratamento hormonal toda a vida - e um tratamento hormonal que é difícil de ajustar. É como ter uma forma muito grave de diabetes. Há muitos efeitos secundários. Rebecca Jordan-Young, que trabalhou com essas pessoas com hiperplasia adrenal congênita, mostra que elas têm órgãos sexuais atípicos - como mulheres com clitóris que se parecem com um pênis - mas que têm ainda muitos outros problemas, como obesidade, pilosidade, problemas cardíacos. Sim, elas têm órgãos sexuais atípicos, mas têm, provavelmente, outros problemas mais importantes.

Caterina: O corpo das mulheres é ainda representado como o mais débil pela medicina e, como tal, mais submisso às formas de medicalização?

llana: Não é representado como mais débil, mas como diferente, com uma norma diferente. Aqui também vejo um processo comparável à cabeça da hidra. Se reconstitui a diferença. Pensa- 
mos por exemplo no caso do câncer e da cirurgia preventiva contra o câncer. Parece uma questão além do gênero, mas na verdade opera só com as mulheres: não se propõe cortar testículos dos homens como forma de prevenção contra o câncer de próstata como se faz com o ovário e o seio das mulheres. Apesar de todos os avanços importantes do feminismo, os esquemas de gênero continuam a plasmar nossa maneira de ver os corpos saudáveis e enfermos.

\section{Referências}

CALLON, Michel; LASCOUMES, Pierre; BARTHE, Yannick. Agir dans un monde incertain. Essai sur la démocratie technique. Paris: Le Seuil, 2001. $358 \mathrm{p}$.

DORLIN, Elsa. La matrice de la race. Généalogie sexuelle et coIoniale de la nation française. Paris: Éditions La Découverte, 2009. $308 \mathrm{p}$.

EDMONDS, Alexander. Pretty Modern. Beauty, Sex and Plastic Surgery in Brazil. Durham/NC: Duke University Press, 2010. $312 \mathrm{p}$.

GARDEY, Delphine; LÖWY, llana. L'invention du naturel. Les sciences et la fabrication du Féminin et du masculin. Paris: Editions de Archives contemporaines, 2000, 227 p.

HACKING, lan. "Making up people." London Review of Books, v. 28, n. 16, p. 161-171, 2006.

HARAWAY, Donna. "A Cyborg Manifesto: Science, Technology, and Socialist-Feminism in the Late Twentieth Century." In:_. Simians, Cyborgs, and Women: The Reinvention of Nature, NewYork, Routledge, 1991. 312 p.

HARDING, Sandra. "El feminismo, la ciencia e las críticas antiluministas". In: NAVARRO, Marysa y STIMPSON, C. R. Nuevas direcciones (compiladoras) Buenos Aires, 2001.

IACUB, Marcela. Le crime était presque sexue: Et outres essais de casuistique juridique. Paris: Flammarion, Coleection Champs, 2002, $272 \mathrm{p}$.

LOCK, Margareth. Encounters with Aging: Mythologies of Menopause in Japan and North America, Berkeley: University of California Press, 1993, 439 p.

"Universalidade da ciência e conhecimentos situados." In: Cadernos Pagu, Campinas, SP: Núcleo de Estudos de Gênero Pagu/Unicamp, n. 15, 2000, p. 15-38.

"Sex on a slide: Antoine Lacassagne and the search for a microscopic definition of masculinity and femininity." History and Philosophy of Life Sciences, v. 35, n. 3, p. 363-378, 2013.

LÖWY, Ilana; ROUCH, Hélène (Orgs.). "La distintion entre sexe ef genere: une histoire entre biologie et culture". Cahier du Genre, n. 34, 2003. 258 p.

MIRLESSE, Véronique; VILLE, Isabelle. "The uses of ultrasonography in relation to foetal malformations." Social Science \& Medicine, Rio de Janeiro, v. 87, issue C, p. 168-175, 2013. 
OUDSHOORN, Nelly. Beyond Natural Body. An Archeology of Sex Hormones, London: Routledge, 1994, 195 p.

ROSENBERG, Charles; GOLDEN, Janet Lynne. Framing Desease. Studies in Cultural History, Rutgers University Press, 1977, 326 p. SHAPIN, Steven; SCHAFFER, Simon. Leviathan and the Air-Pump: Hobbes, Boyle and the Experimental Life. Princeton University Press, 1985, $440 \mathrm{p}$.

STRATHERN, Marilyn. After Nature: English kinship in the late twentieth century. Cambridge: Cambridge University Press, 1992, 240 p.

WELSH, Gilbert; SHWARTZ, Liza Schwartz; WOLOSHIN, Steven. OverDiagnosed. Making People Sick in the Poursuit of Health. Boston: Beacon Press, 2011 , 248 p.

WILLIAMS, Raymond. Keywords: A vocabulary of Culture and Society. USA: Oxford University Press, 1985, 349 p. 